Islamic extremism in the Philippines can be partly traced back to effects of the Afghan war, during which hundreds of Muslim Filipinos, travelled to Pakistan and Afghanistan to join the mujaheddin. It is not clear how many may have been students. The militant Bangsamoro Islamic Freedom Fighters (BIFF) in the Philippines' south has openly pledged allegiance to Islamic State (sometimes called Da'esh), while Abu Sayyaf members were reported among slain jihadists in Syria. Nonetheless, the dean of the University of the Philippines' Institute of Islamic Studies expressed concern that media sensationalism provoked fear and potentially worsened the situation.

Like Indonesia, the Philippines also has used visits by prominent clerics, including from Egypt, recently at Mindanao State University. The visits have been attended by thousands of students and staff, with messages on the five pillars of faith, good governance, and peaceful coexistence with other communities of faith. In an eerie reminder, however, their visits paralleled a firefight between government military and the BIFF, which forced thousands of villagers to flee.

Thailand, too, has its problems with Salafist jihadist groups and with clumsy responses by the Thai military, although there is little evidence of extremist activity in universities in the southern-most border provinces of Yala, Narathiwat, and Pattani.

In Malaysia, an early example was Mohammed Fadly, a student at Universiti Teknologi Malaysia, who, after taking an oath of allegiance to Jemaah Islamiah, sought to fight for Islam in southern Thailand. Recently, increasing tensions between Malaysia's secular constitution and Islam as the state religion provoked a group of leading Malaysians, calling themselves the $\mathrm{G}_{4} \mathrm{O}$, to warn of increasing Islamization. In response to the radicalization of its youth, the Malaysian Islamic Development Department established a cross-agency committee to explain misconceptions surrounding jihad, notably including to Malaysia's universities. A Mahasiswa Islam Tolak Keganasan (Muslim Undergraduates Reject Violence) campaign hopes to use Muslim student leaders at universities to disseminate the real meaning of jihad. Support also has come from clerics in the form of a nationwide fatwa declaring that the call of jihad and martyrdom by Islamic State is un-Islamic. Malaysians who fought for Islamic State and died could not claim to be martyrs.

Malaysia has enhanced the scrutiny of international student applications, via the national agency Education Malaysia Global Services that manages all aspects of international student applications, including passport checks. As a result, rejection rates fell from 28 percent in 2012 , and 24 percent in 2012 , to only 3 percent in 2013 . Nonetheless, despite these efforts, a captured Hamas terrorist recently re- vealed that the organization is actively recruiting young Palestinians studying in Malaysia. In another case, a captured Hamas terrorist revealed that he had been sent to Malaysia, with 9 others, to train using hang gliders, in preparation for terrorist attacks against Israel. Some 40 Palestinian students were said to have been recruited in this manner. The recruitment and associated activities are allegedly centered on the International Islamic University of Malaysia, with one or two of its professors named as having been involved.

\section{Hearts and Minds?}

Such recruitment activities give cause for pause, regarding the success of regional hearts-and-minds campaigns, aimed at countering extremism. Of more than $\mathrm{I} 2,000$ foreigners who joined the fight in Syria last year, perhaps ro percent or more came from Southeast Asia and show the problem remains real. While the above shows that some terrorist recruits are international students (and some domestic), just how many were from the higher education sector remains unknown.

Ultimately, a solid foundation in what it means to be a good Muslim, as well as acceptance of Muslims within the wider society (in the case of Thailand and the Philippines), is needed to counter the attractions of groups such as Islamic State within the region's universities.

But more work remains to be done to counter the effects of extreme Islamist ideologies in the region's universities. If universities are sources of ideas, there is a need to harness this energy to research the phenomenon more fully, work with communities to promulgate a moderate Muslim message of peace and understanding, and promote a more inclusive form of democracy — which can undoubted weaken the appeal of extremism, to impressionable young university students.

\section{Greek Higher Education: Old Challenges and the Current Crisis}

\section{Dimitrios Dentsoras}

Dimitrios Dentsoras is assistant professor at the University of Manitoba, Canada. E-mail: Dimitrios.Dentsoras@umanitoba.ca. This article appeared in a different format in Stepping Into a New Era, edited by A. Glass (European Association for International Education, 2014 Conference Conversation Starter). 
I t is unfortunate that descriptions of the Greek higher education system usually tend to focus on its shortcomings and dysfunctions. This emphasis may be unfair to the individual and collective achievements of Greek academics. Yet, it is also understandable, given the obviousness, size, and longevity of the problems of Greek higher educationand, more importantly, the way in which they reflect the structure and deficiencies of the Greek state. Some of the problems that Greek universities face are so basic that their continued existence is a source of wonder and embarrassment. Until recently, the Ministry of Education could not establish how many students and how many employees Greek universities had, just as the official statistics agency was unable to give an accurate picture of the state's deficit and debt. Greek universities, like many other public institutions, suffer from chronic underfunding, resulting in inadequate infrastructure and services, even basic ones. Yet, the state insists on-often gratuitous-overspending, such as providing books to all students for free, or establishing an ever greater number of universities in small towns that fail to attract any student interest. For the most part, the money seems to be spent unevenly and in an undisciplined manner, relying mostly on criteria of political favoritism. In many ways, this involves mostly public agencies and institutions.

\section{Bad Habits}

Some of the most evident and usual problems of Greek universities have their roots in "bad habits" that Greeks often exhibit in their public life. Such a habit is the tendency of groups and individuals to immediately resort to the most drastic measures to protest or to defend their interests: street demonstrations, strikes, sit-ins, even occupations of public buildings. Courses and research in many Greek universities are regularly brought to a halt when professors, staff members, or students decide to protest for some important reason, most of the time with little opposition from other stakeholders. Greek universities also suffer from the misapplication of a constitutional mandate, which prohibits the police from entering the university grounds without the consent of university authorities - consent that is rarely granted, even if vandalism or blatantly illegal activities take place. This tolerance of forms of demonstration, which often disrupt public life and even forms of illegal activity when it is directed against "the system," is a widespread, characteristically Greek phenomenon.

\section{The Main Problems}

For all its particularities, though, the country's higher education system mainly suffers from the same fundamental problems that plague the country's public life. Two of these problems loom large: overcentralization and the infiltration of party politics into almost every aspect of public and private life. For the most part, these two problems occur in tandem, which aggravates their impact. Among European Union countries, Greece has one of the most centralized system of higher education. Almost every important (and unimportant) decision, from university entrance requirements to the number and structure of universities and departments, to the hiring of everyone employed at the universities goes through the central administration of the Greek Ministry of Education. This has some obvious adverse effects: long delays in decision making and implementation, planning based on insufficient knowledge of particulars, long-reaction times to any kind of crisis, and instability caused by the change of leadership through every political and government cycle. Also, while the ostensible reason for this overcentralization is the establishment of incorruptible, objective controls-thus limiting localized favoritism and nepotism - the result in most cases is exactly the op-

\section{Two of these problems loom large: over- centralization and the infiltration of par- ty politics into almost every aspect of public and private life.}

posite: most decisions are taken through nontransparent dealings and the exchange of political favors.

At the same time, party politics dominate most aspects of Greek higher education. Elections of student representatives and university administrators run along party lines. Party affiliation in universities, for both students and faculty, seems to be a necessary requirement and a facilitator for enjoying all sorts of benefits, from good grades to promotions and to hiring one's friends and relatives. Party politics also spill over to the greater picture of Greek higher education. Local politicians lobby successfully for establishing universities and departments in their districts, regardless of real need; union leaders press for hiring more state employees with the appropriate party affiliation in universities; and all sorts of businessmen vie for lucrative infrastructure or service contracts. The result of such under-the-table dealings, so common in Greek public administration, is inefficiency, overspending, and generally poor-quality services in Greek universities.

\section{Failed Reforms and BackTRACKING Changes}

One would expect that an attempt to improve Greek higher education would start by focusing on these two fundamen- 
tal problems. In fact, the last major attempt to reform Greek higher education, undertaken in 20II, aimed at correcting some of their most evident manifestations, especially those related with the role of party politics in university administration. But the law was never fully implemented, or supplemented by a comprehensive long-term plan to modernize Greek higher education and make it competitive on an international scale. As a result, the planned reforms got bogged down by disagreements regarding relatively minor issues-such as the maximum time for completing a degree-and by intra-university power struggles. Finally, the recently elected Greek government announced its plan to take back the majority of the previous law's reforms and return to the pre-crisis status quo.

\section{Elections of student representatives and university administrators run along party lines.}

The latest developments in the seesaw of Greek educational reforms are baffling, at first sight. A large portion of Greek academics and intellectuals, who vocally opposed the new government's backpedalling, saw the annulment of the previous reforms as an act of revisionism, inspired by outdated leftist ideological convictions. But there are deeper causes, just as in the case of many other reforms that Greece was pushed to make during its fiscal crisis. The most important is the lack of a convincing argument and narrative, as to why reforms are not only necessary but also beneficial in the long run. Many, including the members of the new government, see reforms as a smoke screen for the purely financial objective of limiting government spending-in order to pay off old debts or as an attempt to change the balance of power in Greek universities. In these respects, Greek higher education functions as a mirror for the country as a whole, illustrating the public's increasing distrust toward any new reforms, which are often viewed as attempts to establish external control and to further fiscal austerity. Without a convincing narrative and clear long-term planning, any attempted reform is doomed to be viewed with suspicion and to face a strong opposition to its implementation.

\section{Non-Publishers in European Universities}

\author{
MAREK KWIEK
}

Marek Kwiek is director of the Center for Public Policy Studies and the UNESCO Chair in Institutional Research and Higher Education Policy, University of Poznan, Poland. E-mail: kwiekm@amu.edu.pl.

Tn a traditional account of the scientific community, full1 time academics employed in European universities, who do not conduct research, should not be regarded as part of the scientific community. No publications means no research. No research does not fit the profile of the European university sector - or does it? There are a few hundred thousand non-publishers across European universities. Is non-publishing increasingly becoming compatible with academic work in current massified universities?

The data reported here are drawn from in European countries involved in the "Changing Academic Profession" (CAP) and "Academic Profession in Europe" (EUROAC) surveys: Austria, Finland, Germany, Ireland, Italy, the Netherlands, Norway, Poland, Portugal, Switzerland, and the United Kingdom. We only analyzed the subsample of $(\mathrm{N}=8,886)$ full-time academics working at universities and involved in research.

\section{Cross-country Differentials}

More than 40 percent of Polish academics; and between I5 and 20 percent of Finnish, Portuguese, Norwegian, and German academics-as opposed to less than io percent of Irish, Italian, Dutch, and British academics—are actually research nonperformers. According to surveys performed in the university sector in 2007 or 2010 in various countries, the percentage of full-time employed, self-reported non-publishers is as follows: the Netherlands, 2.7; Italy, 5.4; the United Kingdom, 5.7; Ireland, 9.I; Switzerland, I2.4; Germany, 15.4; Norway, I5.9; Portugal, I8.3; Finland, 20.2. In Poland it is as high as 43.2. The data for Austria: 72.2 percent of nonperformers, seem unreliable and are therefore not commented on here.

Differences in institutional cultures and in national academic cultures lead to other levels of research productivity. Institutions of low academic standing may not value academic research, while institutions of high academic standing may exert normative pressures on academics to get involved in research. Similarly, the normative pressures exerted on academics, to get involved in research in some countries, may be considerably lower than in others; and Poland, until a recent wave of reforms, is a good example. In an age of massified universities, though, perhaps the scale 